\title{
Insecure Whatsapp Chat History, Data Storage and Proposed Security
}

\author{
Robbi Rahim ${ }^{1 *}$, A P U Siahaan ${ }^{2}$, R.Manikandan ${ }^{3}$, Solly Aryza ${ }^{4}$, Nuning Kurniasih ${ }^{5}$, Hardianto Djanggih ${ }^{6}$, Andika Prawira Buana ${ }^{7}$, \\ Roy Marthen Moonti ${ }^{8}$, Ari Riswanto ${ }^{9}$ \\ ${ }^{1}$ Sekolah Tinggi Ilmu Manajemen Sukma, Medan, Indonesia ${ }^{2,4}$ Faculty of Sains and Technology, Universitas Pembangunan \\ Panca Budi, Medan, Indonesia \\ ${ }^{3}$ School of Computing, SASTRA Deemed University,India \\ ${ }^{5}$ Faculty of Communication Science, Library and Information Science Program, Universitas Padjadjaran, Bandung, Indonesia \\ ${ }^{6}$ Universitas Tompotika Luwuk Banggai, Banggai, Indonesia \\ ${ }^{7}$ Universitas Muslim Indonesia, Makassar, Indonesia \\ ${ }^{8}$ Universitas Negeri Gorontalo, Gorontalo, Indonesia \\ ${ }^{9}$ Sekolah Tinggi Ilmu Keguruan dan Ilmu Pendidikan PGRI Sukabumi, Sukabumi, Indonesia \\ 1'usurobbi85@zoho.com, ${ }^{2}$ andiesiahaan@gmail.com, ${ }^{3}$ manikandan75@ core.sastra.edu ${ }^{4}$ sollyaryzalubis@ gmail.com, \\ ${ }^{5}$ nuning.kurniasih@unpad.ac.id, ${ }^{6}$ hardianto.djanggih@gmail.com, ${ }^{7}$ andika.prawira@umi.ac.id, ${ }^{8}$ roymoonti16@gmail.com, \\ aririswanto@stkippgrisukabumi.ac.id
}

\begin{abstract}
Whatsapp is a social media application that is currently widely used from various circles due to ease of use and security is good enough, the security at the time of communicating at this time is very important as well with Whatsapp. Whatsapp from the network is very secure but on the local storage that contains the message was not safe enough because the message on local storage is not secured properly using a special algorithm even using the software Whatsapp Database Viewer whatsapp message can be known, to improve the security of messages on local storage whatsapp submitted security enhancements using the Modular Multiplication Block Cipher algorithm so that the message on whatsapp would be better in terms of security and not easy to read by unauthorized ones.
\end{abstract}

Keywords-Secure Message, Whatsapp Message, Modular, Block Cipher

\section{INTRODUCTION}

Social media is a telecommunication medium used to share information, ideas, files and others that may be useful for others or it can be hoax information that widely spread today especially in Facebook[1], [2]. The development and trend of social media rapidly increase due to the sophisticated technology developments and increasingly easy to use, especially smartphone technology. Social media itself consists of 2 types which is Social Media Site and Social Media Application, social media applications such as Telegram, Instagram, Wechat, Line and WhatsApp[3] are some type of social media applications that are widely used, especially Whatsapp where almost 1.000.000.000 - 1.300.000.000 active user and still growing[4], [5].

Whatsapp at the beginning of its appearance can only be used for private messaging, and with the significant development of whatsapp right now it can be used for messaging in groups, video calls and also voice calls with good quality[6]. Whatsapp recently introduce new features called delete messages for everyone [7] that help users to delete unwanted messages in a certain period of time, there are other features that are quite useful for users it called backup message. Backup messages could be perform in offline (local backup) or online (google drive backup)[6], Whatsapp message backup process will access whatsapp database stored in a file named msgstore-yyyy-mm-dd.1.db.crypt12 (уyyy = year, $\mathrm{mm}=$ month, $\mathrm{dd}=$ date and 12 is an encryption version used).

Whatsapp uses Off the Record, Perfect Forward Secrecy and Double Ratchet Algorithm[8], [9] to secure all message communications on Whatsapp[10] and even databases that are used as data storage as well in passwords using unique keys and it will not same for every device that installed Whatsapp like smartphone android or apple smartphones, by using 3 algorithms for secure message it doesn't mean guarantee the message were safety and not known by others. Tools such as Analyzer for Whatsapp used to analyze words or phrases it take all the data messages that are in Whatsapp application and sent in the form of text to email and maybe there is a function in application to backup data server that developer used[11].

Security[12]-[18] is an important factor in communicating and the use of cryptography or protocol algorithms is very appropriate for use in various communications[19]-[25], the security of communication used in Whatsapp is good and very little attack is performed in this communication line[26], [27], but the messages in data storage of smartphones is not properly secured enough it just the storage only secured with key and the also stored in the smartphone[11] and can be accessed by irresponsible parties using root access.

Rastogi, 2017[27] and Karpisek, 2015[26] who conducted a research on Whatsapp security got a result that Whatsapp network communication is quite safe because the uses of few algorithms used and also the use of End-to-End Encryption and signal protocol to provide comfort to the user when communicating, voice as well as video, but on the user's side the message security on data storage does not guarantee messages free from third-party attacks. Whatsapp Viewer[28] 
is a small tool that can be used to read all messages in data storage very quickly and all messages can be read without any decryption process first, just with Whatsapp database and key obtained from smartphone then Whatsapp message will read all. Improving Whatsapp security is not impossible, this article proposes security as an alternative solution to Whatsapp especially for securing messages on data storage and log history, this article is expected to contribute scientifically to the use of cryptography algorithms as an additional security alternative to Whatsapp.

\section{METHODOLOGY}

The security of the whatsapp application is now very good and reliable, but there are some parts of whatsapp not entirely secure[27], especially on the local storage part as well as logs because extraction can still be done using text mining applications like whatsapp Analyzer[11], [26]. The use of whatsapp Analyzer basically gives application access to mine all messages on whatsapp, the concept of mining can be done by using text mining and this is the same as providing all information on whatsapp messages to third parties legally.

The mechanisms of whatsapp with normal security applied can be seen in Figure 1.

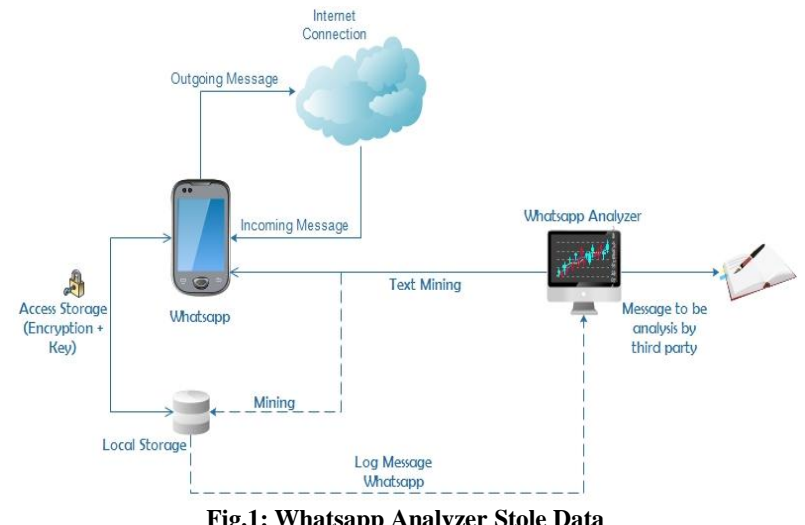

Figure 1 shows the process of accessing local storage using third-party software and reading whatsapp messages you want using the text mining concept, this is probably done because the log whatsapp is not secured with the cryptography algorithm. Messages retrieved by party software may be misused due to poor security of whatsapp.

Another form of data retrieval that can be done is to directly access the local Whatsapp database by using the special tool whatsapp reader database one of which is Whatsapp Database Reviewer[28].

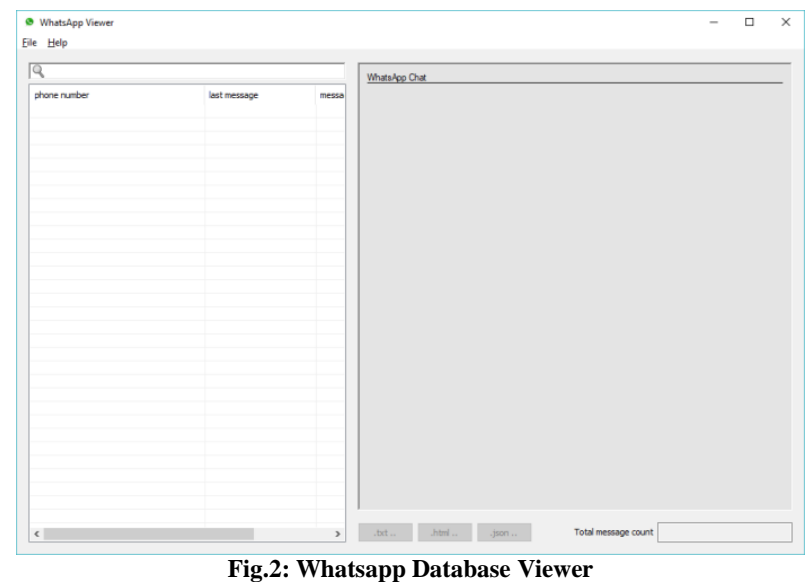

The tool is used to read whatsapp messages are in the local storage whatsapp, the process of retrieving local storage databases and keys can be done in many ways with the tutorials on the internet, and the tool in Figure 2 is used to read messages and no encryption at all.

Description from Figure 1 and Figure 2 prove that local storage on whatsapp is not entirely safe although the communication through on whatsapp network is very safe because it applies many algorithms, to secure messages on logs and local storage given additional algorithm in this case proposed Modular algorithm Multiplication Block Cipher (MMBC) as additional security, here is the proposed mechanism of the MMBC algorithm on whatsapp message security.

1. The MMBC algorithm is symmetric, the algorithm is fast in the process of encryption and decryption compared with some symmetric block cipher cryptography algorithm.

2. The key used is randomized for 4 rounds so that the same message with the same key will produce different ciphertext.

3. Key encryption and decryption using the key activation which is a prime number

4. The message of whatsapp is secured in the local storage record.

5. Encryption and decryption process runs in realtime at the time of incoming and outgoing messages.

\section{RESULT AND DISCUSSION}

Development of security on whatsapp message security is possible to improve the security of the message itself, proposed security that might be done on whatsapp by adding the MMBC algorithm as shown in Figure 3 below: 


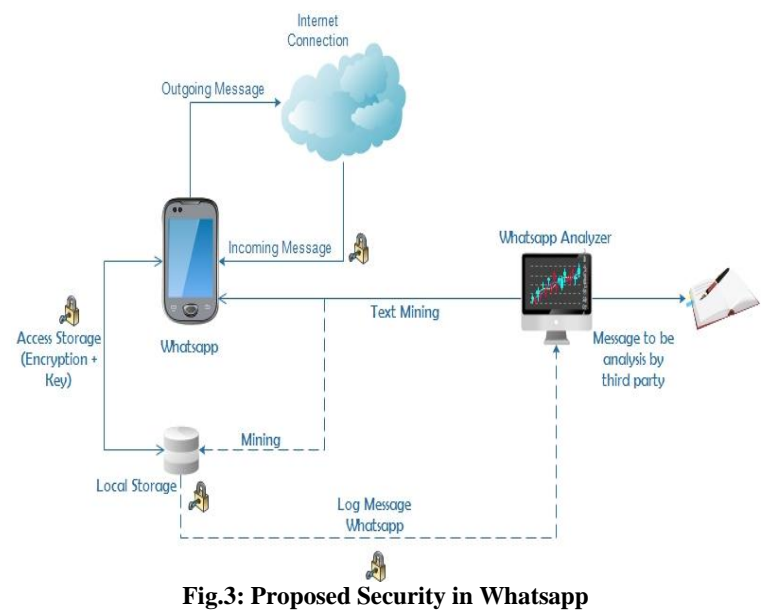

Figure 3 shows the security process on whatsapp in which the message is received in an encrypted state which is automatically stored in the local storage whatsapp in encrypted state, when displayed on the message screen the decryption process is performed and the message is readable by the user but in $\log$ and local storage the message is still in the state encrypted and this can avoid reading messages by irresponsible parties.

Multiplication Block Cipher (MMBC) is a block cipher algorithm with good speed of encryption and decryption process, for example application of MMBC algorithm to whatsapp dpaat seen in the following example:

1. Key Generation

Key $\quad=$ Publikasi oke ya

0101000001110101011000100110110001101001011010 1101100001011100110110100100100000011011110110 101101100101001000000111100101100001

$\mathrm{K}(0)=01010000011101010110001001101100$

$\mathrm{K}(1)=01101001011010110110000101110011$

$K(2)=01101001001000000110111101101011$

$\mathrm{K}(3)=01100101001000000111100101100001$

2. Encryption Process

This encryption process displays step by step message security whatsapp by using MMBC algorithm, berkut is the process.

Plaintext $=$ STIM - SUKMA OKE

Convert to biner:

0101001101010100010010010100110100100000001011 0100100000010100110101010101001011010011010100 000100100000010011110100101101000101

$\mathrm{K}(0)=01010000011101010110001001101100$

$\mathrm{K}(1)=01101001011010110110000101110011$

$K(2)=01101001001000000110111101101011$

$\mathrm{K}(3)=01100101001000000111100101100001$

$\mathrm{X}(0)=01010011010101000100100101001101$

$\mathrm{X}(1)=00100000001011010010000001010011$
$\mathrm{X}(2)=01010101010010110100110101000001$

$\mathrm{X}(3)=00100000010011110100101101000101$

$\mathrm{X}(0)=\mathrm{X}(0) \mathrm{XOR} \mathrm{K}(0)$

$=01010011010101000100100101001101 \quad \mathrm{XOR}$

01010000011101010110001001101100

$=00000011001000010010101100100001$

$\mathrm{X}(1)=\mathrm{X}(1) \mathrm{XOR} \mathrm{K}(1)$

$=00100000001011010010000001010011 \quad \mathrm{XOR}$

01101001011010110110000101110011

$=01001001010001100100000100100000$

$\mathrm{X}(2)=\mathrm{X}(2) \mathrm{XOR} \mathrm{K}(2)$

$=01010101010010110100110101000001 \quad \mathrm{XOR}$

01101001001000000110111101101011 $=00111100011010110010001000101010$

$\mathrm{X}(3)=\mathrm{X}(3) \mathrm{XOR} \mathrm{K}(3)$

$=00100000010011110100101101000101 \quad \mathrm{XOR}$

01100101001000000111100101100001

$=01000101011011110011001000100100$

$\mathrm{X}(0)=\mathrm{C}(0) * \mathrm{X}(0) \mathrm{MOD}\left(\left(2^{\wedge} 32\right)-1\right)$

$=00000010010111110001110011011011 *$

00000011001000010010101100100001

MOD

11111111111111111111111111111111

$=10010001010111011110110100111010$

$\mathrm{X}(1)=\mathrm{C}(1) * \mathrm{X}(1) \mathrm{MOD}\left(\left(2^{\wedge} 32\right)-1\right)$

$=$

0000000000000000000000000100101111100011100110 $110110 * 01001001010001100100000100100000$ MOD

11111111111111111111111111111111

$=10010011100011011111100001101101$

$\mathrm{X}(2)=\mathrm{C}(2) * \mathrm{X}(2) \operatorname{MOD}\left(\left(2^{\wedge} 32\right)-1\right)$

$=$

0000000000000000000000010010111110001110011011 $011000 * 00111100011010110010001000101010$ MOD 11111111111111111111111111111111

$=01001100010000001101011000011011$

$\mathrm{X}(3)=\mathrm{C}(3) * \mathrm{X}(3) \mathrm{MOD}\left(\left(2^{\wedge} 32\right)-1\right)$

$=$

0000000000000000000100101111100011100110110110 $000000 * 01000101011011110011001000100100$ MOD 11111111111111111111111111111111

$=11001110001111111010001110111001$

This process will be loop 3 times and the final result ciphertext as below:

Ciphertext $=$ ótgTi $\left[£ œ F \quad n^{3}\right.$ f $^{\prime}(i$

3. Decryption Process

The MMBC decryption process is used to return ciphertext to plaintext, here is the process.

Ciphertext $=$ ótgTi $\left[£ œ F \quad \mathrm{n}^{3} \mathbf{4}^{\prime}(\mathrm{i}\right.$

Konversi ke biner : 
1111001101110100011001110101010001101001010110 1110100011100111000100011000001001011011100000 110010111110100100100010100010100001

$\mathrm{K}(0)=01010000011101010110001001101100$

$\mathrm{K}(1)=01101001011010110110000101110011$

$\mathrm{K}(2)=01101001001000000110111101101011$

$\mathrm{K}(3)=01100101001000000111100101100001$

$X(0)=11110011011101000110011101010100$

$X(1)=01101001010110111010001110011100$

$\mathrm{X}(2)=01000110000010010110111000001100$

$\mathrm{X}(3)=10111110100100100010100010100001$

$\mathrm{X}(3)=\mathrm{X}(2) \mathrm{XOR} \mathrm{X}(3) \mathrm{XOR} \mathrm{X}(0)$

$=01000110000010010110111000001100$

10111110100100100010100010100001

11110011011101000110011101010100

$=00001011111011110010000111111001$

$\mathrm{X}(2)=\mathrm{X}(1) \mathrm{XOR} \mathrm{X}(2) \mathrm{XOR} \mathrm{X}(3)$

$=01101001010110111010001110011100$

01000110000010010110111000001100

00001011111011110010000111111001

$=00100100101111011110110001101001$

$\mathrm{X}(1)=\mathrm{X}(0) \mathrm{XOR} \mathrm{X}(1) \mathrm{XOR} \mathrm{X}(2)$

$=11110011011101000110011101010100$

01101001010110111010001110011100

00100100101111011110110001101001

$=10111110100100100010100010100001$

$\mathrm{X}(0)=\mathrm{X}(3) \mathrm{XOR} \mathrm{X}(0) \mathrm{XOR} \mathrm{X}(1)$

$=00001011111011110010000111111001$

11110011011101000110011101010100

10111110100100100010100010100001

$=01000110000010010110111000001100$

If $\quad \operatorname{LSB}(X(0))=$

$\operatorname{LSB}(01000110000010010110111000001100)=0=1->$ FALSE

If $\quad \operatorname{LSB}(X(3))=$

$\operatorname{LSB}(00001011111011110010000111111001)=1=0$-->

FALSE

$\mathrm{X}(0)=\mathrm{C}(0) * \mathrm{X}(0)$ MOD $\left(\left(2^{\wedge} 32\right)-1\right)$

$=00001101101011010100011010010100$ *

$01000110000010010110111000001100 \quad$ MOD

11111111111111111111111111111111

$=00001111011001001100100100110101$

$\mathrm{X}(1)=\mathrm{C}(1) * \mathrm{X}(1) \mathrm{MOD}\left(\left(2^{\wedge} 32\right)-1\right)$

$=$

0000011011010110101000110100101000000000000000 000000000000000000

10111110100100100010100010100001

11111111111111111111111111111111

$=11100111110010110111011000111001$

$\mathrm{X}(2)=\mathrm{C}(2) * \mathrm{X}(2) \mathrm{MOD}\left(\left(2^{\wedge} 32\right)-1\right)$

$=$

0001101101011010100011010010100000000000000000

00000000000000
00100100101111011110110001101001

MOD

11111111111111111111111111111111

$=11101000110010111001110011000101$

$\mathrm{X}(3)=\mathrm{C}(3) * \mathrm{X}(3) \operatorname{MOD}\left(\left(2^{\wedge} 32\right)-1\right)$

$=$

0001101101011010100011010010100000000000000000 $0000000000 * 00001011111011110010000111111001$ MOD 11111111111111111111111111111111 $=00100011110010001110001111100101$

This process is done as much as 3 times the permutation until the plaintext is obtained.

Encryption and decryption process with MMBC algorithm is done by using XOR function so it does not require long time for system to process and security improvement can be done better.

\section{CONCLUSION}

Whatsapp is very secure now and there may be no need for security additions but the storage of messages on local storage on whatsapp is still possible to read with the help of special software, this weakness can be overcome by providing added security in this case using MMBC algorithm, the test proved that message security on local storage whatsapp can be done well and maximally.

\section{REFERENCES}

[1] J. K. Riley, "Liking the Lies: An Analysis of Hoaxes on Facebook and What They Mean for the Contextual Framework of Viral Message Spread | Response," 2017. [Online]. Available: https://responsejournal.net/issue/201706/article/liking-lies-analysis-hoaxes-facebook-and-whatthey-mean-contextual-framework. [Accessed: 31-Mar2018].

[2] J. Evans and A. Rzhetsky, "Machine science," Science, vol. 329, no. 5990. pp. 399-400, 2010.

[3] E. Winarko and A. Cherid, "Recognizing the Sarcastic Statement on WhatsApp Group with Indonesian Language Text," in International Conference on Broadband Communication, Wireless Sensors and Powering (BCWSP), 2017, pp. 1-6.

[4] T. Sutikno, L. Handayani, D. Stiawan, M. A. Riyadi, and I. M. I. Subroto, "WhatsApp, Viber and Telegram which is Best for Instant Messaging?," Int. J. Electr. Comput. Eng., vol. 6 , no. 3, p. 909,2016

[5] P. Kallas, "Top 15 Most Popular Social Networking Sites and Apps [February 2018] @DreamGrow 2018," 2018. [Online]. Available: https://www.dreamgrow.com/top-15most-popular-social-networking-sites/. [Accessed: 31-Mar2018].

[6] WhatsApp, “WhatsApp Features," WhatsApp, 2017. [Online]. Available: https://www.whatsapp.com/features/.

[7] A. Admin, "WhatsApp FAQ - Deleting messages." [Online]. Available: https://faq.whatsapp.com/en/android/26000068/. [Accessed: 31-Mar-2018].

[8] M. Bellare, A. C. Singh, J. Jaeger, M. Nyayapati, and I. Stepanovs, "Ratcheted Encryption and Key Exchange: The Security of Messaging," 2017. 
[9] P. Rösler, C. Mainka, and J. Schwenk, "More is Less: On the End-to-End Security of Group Chats in Signal, WhatsApp, and Threema," 2018.

[10] M. Ganguly, "WhatsApp vulnerability allows snooping on encrypted messages," The Guardian, 2017.

[11] S. Sahu, "An Analysis of WhatsApp Forensics in Android Smartphones," Int. J. Eng. Res., vol. 5013, no. 3, pp. 349$350,2014$.

[12] R. Rahim, "Man-in-the-middle-attack prevention using interlock protocol method," ARPN J. Eng. Appl. Sci., vol. 12, no. 22, pp. 6483-6487, 2017.

[13] A. Putera, U. Siahaan, and R. Rahim, "Dynamic Key Matrix of Hill Cipher Using Genetic Algorithm," Int. J. Secur. Its Appl., vol. 10, no. 8, pp. 173-180, Aug. 2016.

[14] S. Sriadhi, R. Rahim, and A. S. Ahmar, "RC4 Algorithm Visualization for Cryptography Education," J. Phys. Conf. Ser., vol. 1028, no. 1, p. 012057, Jun. 2018.

[15] H. Nurdiyanto, R. Rahim, A. S. Ahmar, M. Syahril, M Dahria, and H. Ahmad, "Secure a Transaction Activity with Base64 Algorithm and Word Auto Key Encryption Algorithm," J. Phys. Conf. Ser., vol. 1028, no. 1, p. 012053 , Jun. 2018.

[16] R. Rahim, D. Adyaraka, S. Sallu, E. Sarimanah, and M. M. Rahman, "Tiny encryption algorithm and pixel value differencing for enhancement security message," Int. J. Eng. Technol., vol. 7, no. 2.9, pp. 82-85, 2018.

[17] R. Rahim, D. Adyaraka, S. Sallu, E. Sarimanah, and A. Hidayat, "An application data security with lempel - ziv welch and blowfish," Int. J. Eng. Technol., vol. 7, no. 2.9, pp. 71-73, 2018.

[18] R. Rahim, M. Dahria, M. Syahril, and B. Anwar, "Combination of the Blowfish and Lempel-Ziv-Welch algorithms for text compression," World Trans. Eng. Technol. Educ., vol. 15, no. 3, pp. 292-297, 2017.

[19] H. Nurdiyanto, R. Rahim, and N. Wulan, "Symmetric Stream Cipher using Triple Transposition Key Method and Base64 Algorithm for Security Improvement," J. Phys. Conf. Ser., vol. 930, no. 1, p. 012005, Dec. 2017.

[20] H. Nurdiyanto and R. Rahim, "Enhanced pixel value differencing steganography with government standard algorithm," in 2017 3rd International Conference on Science in Information Technology (ICSITech), 2017, pp. 366-371.

[21] D. Nofriansyah et al., "A New Image Encryption Technique Combining Hill Cipher Method, Morse Code and Least Significant Bit Algorithm," J. Phys. Conf. Ser., vol. 954, no. 1, p. 012003, 2018.

[22] E. Kartikadarma, T. Listyorini, and R. Rahim, "An Android mobile RC4 simulation for education," World Trans. Eng. Technol. Educ., vol. 16, no. 1, pp. 75-79, 2018

[23] . R. et al., "Visual Cryptography with RSA Algorithm for Color Image," Int. J. Eng. Technol., vol. 7, no. 2.5, pp. 6568, Mar. 2018.

[24] R. Rahim, N. Kurniasih, M. Mustamam, L. Andriany, U. Nasution, and A. H. Mu-, "Combination Vigenere Cipher and One Time Pad for Data Security," Int. J. Eng. Technol., vol. 7, no. 2.3, pp. 92-94, 2018.

[25] H. Djanggih, H. Thalib, H. Baharuddin, N. Qamar, and A. S. Ahmar, "The Effectiveness of Law Enforcement on Child Protection for Cybercrime Victims in Indonesia," J. Phys. Conf. Ser., vol. 1028, p. 012192, Jun. 2018.

[26] F. Karpisek, I. Baggili, and F. Breitinger, "WhatsApp network forensics: Decrypting and understanding the WhatsApp call signaling messages," Digit. Investig., vol. 15 , pp. 110-118, 2015.
[27] N. Rastogi and J. Hendler, "WhatsApp security and role of metadata in preserving privacy," arXiv Prepr. arXiv1701.06817, pp. 269-275, 2017.

[28] A. Mausch, "WhatsApp Viewer." [Online]. Available: http://andreas-mausch.de/whatsapp-viewer/. [Accessed: 01Apr-2018]. 
